\title{
Memoria, cuerpo y silencio: El caso "María Soledad" y la demanda de ciudadanía en la Argentina de los noventa
}

\author{
Marcelo Bergman y Mónica Szurmuk
}

\begin{abstract}
Este artículo analiza el origen y las estrategias de representación desarrolladas por el movimiento social surgido alrededor de un caso de feminicidio en el norte de la Argentina en la década de 1990. Se lee el movimiento en el contexto de los movimientos de derechos humanos de las décadas del setenta y ochenta y se propone que estos nuevos movimientos sociales se ubican en el espacio de la subalternidad en búsqueda de derechos específicos y no de cambios sociales radicales.

This article analyzes the origin and strategies of representation developed by a social movement that originated in response to a case of feminicide in the north of Argentina in the 1990s. We read the movement in the context of human rights organizations of the 1970s and 1980s, and we propose that these social movements occupy the space of the subaltern in search of specific rights instead of major and radical social changes.
\end{abstract}



Marcelo Bergman

Centro de Investigación y Docencia Económicas

Mónica Szurmuk

Instituto de Investigaciones Doctor José María Luis Mora

Memoria, cuerpo y silencio: el caso "María Soledad" y la demanda de ciudadanía en la Argentina de los noventa ${ }^{1}$

\section{Introducción}

Este ensayo estudia el proceso por el cual el asesinato de una joven en el norte de la Argentina en la década de 1990 suscitó un movimiento social que puso a prueba las prácticas de los recién establecidos gobiernos democráticos de la región. Para llevar a cabo este estudio, exploramos las complejas relaciones entre el cuerpo femenino y la construcción de la idea de ciudadanía. Mostramos cómo las imágenes de raza, género y clase figuran en la construcción de la resistencia. Argumentamos que este movimiento fue un fenómeno nuevo en Argentina donde, siguiendo el modelo de las Madres de la Plaza de Mayo, tenía la intención de reclamar derechos civiles y de dramatizar este reclamo al situarlo en el cuerpo violado. Nuestro estudio examina el camino hacia la adquisición de derechos civiles por

${ }^{1}$ Una versión anterior de este trabajo fue publicada en inglés en el Latin American Subaltern Studies Reader, editado por Ileana Rodríguez. La traducción al español fue realizada por los autores. 
miembros de grupos subalternos que caracteriza el proceso de redemocratización en el Cono Sur. Este reclamo por derechos civiles es también un movimiento hermenéutico hacia una lectura diferente del cadáver, una lectura que extiende la ciudadanía y cambia el modo de entenderla. Dado que los particulares del caso no se conocen perfectamente fuera de Argentina, empezaremos con un recuento de los "hechos".

\section{La narrativa legal}

En esta sección presentamos un resumen de los hechos que llevaron a la muerte a María Soledad Morales, utilizando información que se hizo disponible a través del proceso legal así como de los medios de comunicación. Este recuento también se basa en tres libros que fueron publicados para documentar el caso. Dos de ellos — No llores por mí, Catamarca por Rey y Pazos, y Catamarca de Norma Morandini-son acusaciones abiertas a la familia gobernante de Catamarca escritas por periodistas que cubrieron el caso. Un tercer libro -Dieciocho años de Soledad - es un panfleto amarillista que juega con las conexiones entre el erotismo y la violencia en el caso. También llevamos a cabo entrevistas con Fanny Mandelbaum, una de las periodistas que cubrió los particulares del caso para el Canal 11 en Buenos Aires, y con la monja Martha Pelloni, quien organizó las Marchas del Silencio. El recuento que sigue tiene la intención de incluir estas distintas voces y de explorar los huecos en las narrativas, en aquellos lugares donde aparecen los prejuicios.

María Soledad Morales tenía diecisiete años, era una estudiante promedio del Colegio Católico del Carmen y San José, y su sueño era convertirse en modelo. Era la segunda de siete hijos de una familia de clase media trabajadora de la ciudad de Catamarca. Su padre, como casi la mitad de los habitantes de la ciudad, era un empleado público. 
La ciudad de Catamarca se encuentra a 1200 kilómetros al noroeste de Buenos Aires. La mitad de los 240000 habitantes de la provincia de Catamarca vivían en esta ciudad cuando fue asesinada María Soledad. La familia Saadi había gobernado la provincia casi ininterrumpidamente desde 1949, cuando el primer Vicente Saadi fue elegido gobernador durante la primera presidencia de Juan Domingo Perón. En 1990, en el momento de la muerte de María Soledad, Ramón Saadi, hijo de Vicente y peronista como su padre, era el gobernador de la provincia. El gobierno provincial se caracterizaba por el nepotismo, y cada uno de los miembros de la familia Saadi tenía una posición de poder. Se cree que María Soledad murió en una fiesta en la casa de Ángel Luque, un diputado que llegó al poder como secretario de Vicente Saadi. La fiesta, a la cual acudieron hombres jóvenes cercanos a los círculos de poder, había sido organizada por Guillermo, hijo de Ángel Luque.

En la noche del sábado 8 de septiembre, María Soledad envió un mensaje a su novio Luis Tula donde le solicitaba que pasara a buscarla a un evento para reunir fondos de su escuela. Ella quería pasar la noche con él. Luis Tula tenía veintinueve años y era casado, pero él y su mujer mantenían en secreto su matrimonio. Tula había mentido sobre su soltería cuando inició su relación con María Soledad, pero en el momento de su muerte, María Soledad tenía conocimiento acerca de su situación marital y ya había tenido diversos enfrentamientos acalorados con la esposa de Tula. Los Tula fueron los primeros sospechosos en la investigación policial. Tula vio a María Soledad la noche de su muerte pero no se fue con ella. Según su declaración, él no habría querido a una mujer "que olía a pescado" (hablaremos de esto más adelante). María Soledad caminó hacia la parada del autobús. Fue vista por última vez al abordar un automóvil que pertenecía a Arnaldito Saadi, uno de los sobrinos del gobernador. 
Horas después de la desaparición de María Soledad, Alicia Cubas, viuda de Vicente Saadi y madre del gobernador, hizo la siguiente declaración: "Se le murió una chinita al hijo de Luque". Chinita es una palabra que se utiliza peyorativamente al referirse a una mujer de las provincias, ${ }^{2}$ de piel oscura y en general de clase trabajadora. En su sarcasmo racista, Alicia Cubas no podría haber sospechado que el caso atraería una destacada atención tanto a nivel nacional como internacional, y que cambiaría el mapa político de Catamarca para siempre, pues obligaría al gobierno central a intervenir en la administración de la provincia y finalmente desautorizaría al gobernador constitucionalmente electo. ${ }^{3}$ Tres extensas investigaciones se llevaron a cabo sin obtener resultados concluyentes. La familia Saadi, quien había conseguido mantener el control político de Catamarca por más de 40 cuarenta años, perdió la elección en 1992 como consecuencia directa del escándalo alrededor del "caso María Soledad", como se lo conoció legalmente. Un juicio en 1996 fue anulado cuando, uno por uno, todos los jueces de la provincia se declararon incompetentes para presidir el juicio debido a conexiones sospechosas con los acusados. El juicio final se llevó a cabo en 1998, ocho años después del asesinato, y tanto Luis Tula como Guillermo Luque fueron declarados culpables.

Por más de un año después de su muerte, Martha Pelloni, la monja directora del Colegio del Carmen y San José, organizó marchas de protesta semanales con apoyo de la jerarquía eclesiástica local. Las marchas simbolizaban el nacimiento de un

\footnotetext{
${ }^{2}$ Los comentarios de Alicia Cubas están incluidos en Rey y Pazos 1991 y en Morandini 1991.

${ }^{3}$ El presidente Menem utilizó la figura "intervención provincial” que lo autorizaba como presidente a remover a las autoridades provinciales constitucionalmente electas bajo el argumento de preservar el "orden público". En esencia, Menem, quien se había visto fuertemente beneficiado por el apoyo de la familia Saadi, tuvo que ceder en esta alianza política para hacer frente a las presiones parlamentaria y de la opinión pública.
} 
nuevo tipo de movilización social. Miles de manifestantes se reunían en manifestaciones pacíficas a favor del esclarecimiento de la muerte de la joven y la sanción de los asesinos en lo que se conoce como "marchas del silencio". La sospecha de que el caudillismo tradicional familiar había estado involucrado tanto en el homicidio como en el encubrimiento que lo siguió, generó una indignación popular que excedió lo estimado por las autoridades locales. Se pusieron en jaque los patrones clientelares tradicionales de control social y la movilización de base logró desmantelar la hegemonía de este tradicional bastión peronista. El sistema político cuasifeudal de la familia Saadi, el sindicalismo peronista, y el liderazgo político corrupto se enfrentó al surgimiento de un movimiento social en el cual ciertos individuos por primera vez sintieron que tenían el derecho básico de protección igualitaria ante la ley. El caso María Soledad representa el surgimiento de un movimiento subalterno en favor de la ciudadanía. El caso también ejemplifica nuevas tendencias contrahegemónicas de movilización popular, y una nueva narrativa en la dilucidación de los roles de género.

En este artículo, analizamos este caso a la luz de importantes desarrollos tanto nacionales como locales. El caso sucede siete años después de la transición a la democracia en Argentina, en el contexto de una agudísima crisis económica, y en la coyuntura de importantes transformaciones sociales y culturales tanto en las grandes ciudades como en las provincias. Nuestro argumento es que un caso como este no hubiera tenido las ramificaciones que tuvo si los patrones políticos y culturales tradicionales hubiesen estado en su lugar. Sin embargo, el nuevo clamor por protecciones ciudadanas lleva a que cobre interés nacional e internacional un caso que podría haber sido relegado a las páginas policiales de un diario provincial. Las peculiaridades de este caso pusieron en el centro del debate político temas candentes en la inmediata posdictadura en la Argentina. 
Comenzaremos el análisis con una discusión de ciertos conceptos teóricos como la democratización, la ciudadanía y movimientos sociales, que servirán para entender el fenómeno. Posteriormente se analizarán las estrategias de representación del movimiento social en Catamarca.

\section{Democratización y Estado}

El caso María Soledad ha sido analizado ampliamente en el contexto del proceso de redemocratización en Argentina. ${ }^{4}$ Nuestro argumento es que a pesar de que la democratización política influyó en dichos eventos, este caso debe ser leído trascendiendo la discusión de la democratización. El corpus de la literatura sobre la transición hacia la democracia en América Latina ha sido extensa. ${ }^{5}$ Desde mediados de la década de los ochenta del siglo pasado, se ha teorizado la democracia como un antídoto al fracaso de las formas políticas de la década del setenta, particularmente la brutal represión de los regímenes militares. O'Donnell y Schmitter ${ }^{6}$ han concebido la democracia como un "juego" en el cual los actores (fuerzas sociales y políticas) aceptan derrotas si, en el futuro cercano, vislumbran una recompensa. La democracia es la única posibilidad viable cuando la incertidumbre de los resultados políticos se institucionaliza. ${ }^{7}$

En este paradigma, la democratización es concebida como el proceso de la construcción de instituciones capaces de canalizar y articular intereses y demandas. La democracia también se

${ }^{4}$ Los artículos de periódicos y libros que narran esta historia, relacionan la caída de la hegemonía de la familia Saadi en Catamarca con un proceso más amplio de liberación política

${ }^{5}$ Un buen repaso de esta literatura puede encontrarse en Diamond 1992 y Mainwaring et al. 1999.

${ }^{6}$ Véase O’Donnell y Schmitter 1986.

${ }^{7}$ Véase Przeworski 1991. 
entiende como la competencia por el poder y por la rendición de cuentas de los gobiernos. Las democracias se consolidan cuando la amenaza de una vuelta a los regímenes dictatoriales se desvanece. Tal definición de democracia continúa siendo persuasiva para explicar las transiciones de las dictaduras militares hacia regímenes más representativos en América Latina. Sin embargo, la institucionalización de las democracias de ninguna manera explica el surgimiento exitoso de nuevos movimientos sociales y de lucha por la ciudadanía. ${ }^{8}$ La democracia podrá ser la única alternativa pero quizá no cumpla las demandas de los actores sociales, quienes, como resultado de las transformaciones sociales y culturales, empiezan a reclamar nuevos derechos. En otras palabras, las débiles instituciones de representación que existen en las nuevas democracias en toda América Latina parecen no amenazar la estabilidad de los sistemas políticos, pero sí socavan su rango de gobernabilidad. Las democracias pueden estar en el proceso de consolidación política, pero también muestran señales de su incapacidad para responder a demandas sociales básicas como los derechos civiles y económicos. Esto conduce hacia tipos híbridos de democracias, como la democracia delegativa de O'Donnell o la democracia tutelar de Touraine. ${ }^{9}$

Una limitación importante del debate sobre la democratización es que no se lo ha encuadrado dentro del debate del Estado. Dado que los politólogos han concebido a la democracia básicamente como un régimen, la democracia como sistema realmente nunca se ha entendido o interpretado como tal. Por lo tanto, el surgimiento de retos no institucionalizados hacia la

\footnotetext{
${ }^{8}$ Véase Escobar y Álvarez 1992; Foweraker 1995.

9 Tanto O'Donnell (1993) como Touraine enfatizan las limitaciones de un sistema político que no es capaz de responder a las necesidades económicas y legales de amplios segmentos de la población. Por ejemplo, en Argentina, la democracia posterior a 1983 es más estable que los sistemas democráticos previos, pero no se asemeja al sistema integrativo de Europa occidental; en otras palabras, es una democracia con derechos limitados.
} 
autoridad central es concebido como insurgencia. Sin embargo, ejemplos como el de la movilización de María Soledad, el surgimiento de la CONAIE en Ecuador, o las organizaciones vecinales en Brasil no encajan en la categoría de insurgencia, a pesar de que representan retos a la efectividad de las democracias. Consecuentemente el debate tradicional de las transiciones debe trascenderse para enfrentar los retos expuestos por los movimientos populares.

La fortaleza del Estado se ha convertido en la clave para analizar los conflictos sociales y sus resoluciones. Pero ¿cómo se determina dicha fuerza? Proponemos definir fortaleza estatal como un conjunto de instituciones capaces de ofrecer bienes y servicios de acuerdo con la ley. Esta definición operativa establece una relación directa entre las leyes y su grado de aplicabilidad. A través del tiempo, el Estado expande su cuerpo legal y consecuentemente debe extender también su capacidad de control. Un Estado es considerado fuerte en tanto y en cuanto haga cumplir sus leyes dentro de los mismos límites y procedimientos que las mismas leyes determinan. Todavía hoy los Estados están bajo una fuerte presión para proporcionar un amplio rango de bienes y servicios. La clave de su fortaleza es su capacidad de canalizar dichas presiones a través de legislación que se pueda instrumentar y dentro de la cual se pueda actuar.

Ningún Estado puede ser totalmente fuerte dado que ningún Estado provee todos los bienes y servicios que sus propias leyes prescriben y ningún Estado puede aplicar uniformemente sus leyes. Por lo tanto, la fortaleza es una cuestión de grado. Más aún, al ser las leyes la resolución parcial de conflictos sociales, ${ }^{10}$ cambian a través del tiempo de acuerdo con las configuraciones sociales y con las relaciones de poder. Sin embargo, los Estados modernos son generalmente concebidos como proveedores de bienes y servicios. Éstos son los servicios bá-

${ }^{10}$ Chambliss 1982; Cotterrell 1984. 
sicos que permiten al Estado pasar el umbral de fortaleza. Ésta es la fuente de la debilidad de los Estados latinoamericanos. ${ }^{11}$ Éstos no han respetado históricamente los derechos de los ciudadanos en la región, y la legalidad ha sido históricamente violada marginal o consistentemente. La anomia no es un fenómeno nuevo en América Latina. Lo novedoso es la forma que toman las demandas ciudadanas para un mayor cumplimiento de la ley. ${ }^{12}$

Es evidente que las democracias en América Latina niegan derechos civiles a amplios sectores de la población. O’Donnell afirma:

La democracia no es sólo un régimen político sino también una forma muy particular de relación entre el Estado y los ciudadanos... bajo un tipo de estado de derecho, que además de la ciudadanía política sostiene también la ciudadanía civil y una red de rendición de cuentas. ${ }^{13}$

Habermas también ha enfatizado que el papel que juegan las leyes en las democracias es de fudamental importancia. Los derechos civiles deben ser universales y efectivamente protegidos por la ley para poder ser considerados compatibles con la democracia. La singularidad de la historia de América Latina se debe a que la ciudadanía política fue otorgada antes de que los derechos civiles estuviesen efectivamente protegidos. Este proceso es opuesto al realizado por las naciones europeas, donde los derechos civiles y la protección de la ley se

${ }^{11}$ O’Donnell 1993.

${ }^{12}$ Otros ejemplos en Argentina incluyen las asambleas de los lunes enfrente al edificio de la Corte en Buenos Aires organizada por Memoria Activa para demandar el esclarecimiento del bombardeo de las oficinas generales de los Servicios Sociales Judíos en Buenos Aires, las manifestaciones de los familiares de las víctimas de actos de brutalidad policiaca en los suburbios de Buenos Aires, la movilización en Cutral-Có después del cierre de la compañía petrolera estatal en la ciudad y las marchas de los familiares de las víctimas del incendio en la discoteca Cro-Magnon.

${ }^{13}$ O’Donnell 1999, 321 (la traducción es nuestra). 
otorgaron universalmente antes que los derechos políticos (el derecho al voto y de asamblea). ${ }^{14}$ Más aún, en Argentina, algunos derechos sociales fueron otorgados (particularmente bajo gobiernos populistas) mientras que los derechos civiles eran consistentemente violados, y el estado de derecho estaba seriamente socavado.

Las protestas alrededor del asesinato de María Soledad fueron precisamente un clamor por el estado de derecho, los derechos civiles y la rendición de cuentas, y estaban, en ese sentido, en línea con las protestas inauguradas por las Madres de la Plaza de Mayo.

\section{Movimientos sociales}

El paradigma fundacional de la teoría de acción colectiva ${ }^{15}$ enfatiza la motivación orientada a la meta del colectivo. Los agentes sociales o actores colectivos, incluyendo el movimiento popular de Catamarca, actúan de acuerdo con sus metas. El éxito de un movimiento está determinado por la capacidad de alcanzar estos objetivos. Sin embargo, las metas están delineadas por las expectativas que se agregan en demandas concretas. Lo que activa a los agentes sociales es la articulación de dichas expectativas y la forma en que modela un nuevo discurso. Los procesos de modernización y globalización han impulsado transformaciones dramáticas en las expectativas de las personas. En otras palabras, las transformaciones culturales introducidas por la modernización y globalización han activado una revolución de expectativas. Se esperaba que

${ }^{14}$ Hay dos excepciones:

1. A las mujeres, en la mayoría de los casos, les fueron otorgados los derechos civiles después de que los derechos políticos les fueran otorgados a los hombres.

2. La institución de la esclavitud en los Estados Unidos coexistió con los derechos civiles y políticos universales para el hombre blanco.

15 Olson 1965; Elster 1989. 
el Estado fuera capaz de proveer lo que ha fracasado en otorgar a través del tiempo: derechos civiles y sociales.

Los Estados en América Latina son muy débiles. Debido a que los cambios en las expectativas tienden a aumentar la presión hacia un mayor conjunto de derechos, y que los Estados son incapaces de proveerlos, existe un campo fértil para el surgimiento de acciones colectivas que apuntan su movilización hacia metas concretas más que a importantes transformaciones como son las revoluciones sociales. Los movimientos sociales en América Latina son generalmente reacciones de subalternos ante derechos incumplidos. Su lucha representa la contraparte de la debilidad del estado y la ciudadanía efectiva.

Sin embargo, el concepto de derechos debe de ser entendido más allá de la clásica formulación sociológica. ${ }^{16}$ En este enfoque, los derechos son iniciativas del Estado para incluir nuevos grupos sociales en el orden político. Esta explicación de arriba hacia abajo desestima el campo fértil de los grupos subalternos y los procesos sociales que construyen una dimensión diferente de la ciudadanía. Los derechos no son únicamente un atributo natural otorgado por el Estado, sino una demanda por espacios y reconocimiento de los propios individuos.

En Consumidores y ciudadanos, Néstor García Canclini señala que la ciudadanía no es únicamente un concepto jurídico de derechos sustantivos. Más que valores abstractos, los derechos deben ser concebidos como un proceso de construcción que cambia en función de las prácticas y los discursos. Por lo tanto, la ciudadanía y los derechos no se refieren únicamente a la estructura formal de la sociedad sino también a la lucha de otros individuos que tienen "intereses válidos, valores pertinentes

\footnotetext{
${ }^{16}$ La formulación sociológica estándar fue adelantada por T. H. Marshall. Los derechos en los Estados de Europa occidental fueron otorgados en una secuencia donde primero se extendieron los derechos civiles y luego los derechos políticos (particularmente la expansión del derecho del voto), y finalmente, para mediados del siglo xx, los derechos sociales (principalmente educación y seguridad social). Como ya se dijo, en América Latina la expansión no siguió el orden.
} 
y demandas legítimas". Por lo tanto, "se concibe a los derechos como expresión de un orden estatal y como una gramática civil". ${ }^{17}$

En suma, los movimientos sociales como el generado por el caso de María Soledad no son ni prodemocráticos ni antidemocráticos, sino claramente proderechos. Promueven indirectamente la democracia en su reclamo en favor de la ciudadanía y a largo plazo se oponen a todo régimen dictatorial. Es precisamente la movilización de la sociedad civil lo que establece una nueva agenda y, como casi cualquier movimiento social, toma a todo el mundo por sorpresa, precisamente porque enfrenta a los patrones tradicionales de control social. La movilización en Catamarca surgió como un alto en la tendencia continua del clientelismo político, el conservadurismo social, y la pauperización ejemplificando la discontinuidad del legado anterior. La democracia y la modernización impulsaron nuevas expectativas que enfrentaron los patrones tradicionales de control. Se desarrolló una nueva crisis dado que el Estado era incapaz de enfrentar las nuevas demandas de la sociedad civil.

\section{Nuevos actores y motivos}

Las movilizaciones masivas, la protesta social y la lucha armada marcaron la historia de Argentina. Muchos de estos movimientos han moldeado las instituciones políticas y sociales del país. La larga tradición de protesta social encuentra un elemento de continuidad en los eventos de Catamarca; sin embargo, estos eventos también estuvieron marcados por un cambio en las movilizaciones de masas tradicionales. Las demandas por un estado de derecho efectivo y por la rendición de cuentas se volvieron nuevas modalidades de participación pública.

${ }^{17}$ García Canclini 1995, 20. 
Las Marchas del Silencio no hubieran podido suceder en la Argentina anterior a 1976. A diferencia de los movimientos revolucionarios de los años sesenta y de inicios de los setenta, las marchas del silencio fueron producto del surgimiento de nuevos actores sociales que reclaman derechos civiles específicos sin buscar un cambio social radical. Los manifestantes de Catamarca son herederos de las organizaciones de derechos humanos como las Madres de la Plaza de Mayo y son producto de una sociedad donde las ideas sobre política, leyes y acción pública han cambiado radicalmente. La brutalidad y la sofisticación que desplegaron los militares en contra de ciudadanos para mantener el poder desde 1976 hasta diciembre de 1983 requirieron nuevas estrategias para la resistencia. Las Madres de la Plaza de Mayo inauguraron una nueva forma de hacer política. Pelearon en contra de la fuerza y las armas de los militares con su propia presencia, desafiando la prohibición de manifestaciones públicas. Sus caminatas alrededor de la Plaza de Mayo cada jueves simbolizaron un nuevo tipo de resistencia anclada con los papeles tradicionales de las mujeres — maternidad y autosacrificiopero socavando características esenciales de aquellos papeles tales como lo privado, la sumisión y la pasividad.

Las Madres pelearon con sus propios cuerpos que ofrecieron como evidencia de la existencia de los hijos e hijas que el régimen había "desaparecido". Ellas habían parido a esos hijos, y ahora, en su ausencia, tenían que hablar por ellos y renacerlos nuevamente tanto en palabras como en ideas. Para incorporar la presencia de sus hijos en la vida del país, las Madres usan estrategias con las que buscan incorporar el cuerpo de los desaparecidos al paisaje del país. En distintas manifestaciones, las mujeres han utilizado siluetas de papel, máscaras, manos de papel y figuras humanas dibujadas en el pavimento para ayudar a que el público perciba físicamente la ausencia de sus hijos. ${ }^{18}$

18 Jean Franco, en su artículo "Killing Nuns, Priests, Women, and Children", se refiere en términos similares al espacio que ocupan los desaparecidos, como 
La insistencia en el cuerpo humano no sorprende en un país donde el cuerpo se ha convertido en sitio de opresión. Lo que hicieron las Madres fue transformar sus propios cuerpos, su propia presencia pública en un homenaje a sus hijos. Ellas respondían a un sistema que había invadido su vida privada y en respuesta socializaron su dolor y transformaron en suyas las calles y la Plaza de Mayo en el corazón de la vida política y económica del país. El ejemplo político ofrecido por las Madres de la Plaza de Mayo, así como otras organizaciones de derechos humanos, tales como las Abuelas de la Plaza de Mayo, sirvieron para modelar nuevas formas de resistencia y también para informar al público sobre distintas formas de entender la opresión.

Cuando el cuerpo de María Soledad Morales apareció en Catamarca, la gente usó el modelo de las Madres en dos formas: 1) mediante la información diseminada por las organizaciones de derechos humanos se pudo interpretar la muerte de María Soledad como un acontecimiento político, y a través de la educación sobre la naturaleza de las violaciones de los derechos humanos se pudo interpretar la violación y la mutilación no como tragedias individuales sino modos en que los poderosos ejercían el control; 2) las marchas del silencio fueron inspiradas por las marchas pacíficas y silenciosas de las Madres de Plaza de Mayo. Las Madres también fungieron como modelos de luto público y de socialización y politización del dolor.

\section{El silencio}

Las Marchas del Silencio fueron la articulación de la resistencia en contra de un sistema económico y político. Criticaban

su amiga Alaíde Foppa: "Hasta hoy Alaíde 'continúa desaparecida' en las palabras de un periódico, como muchos otros hombres, sacerdotes, monjas e hijos en América Latina que no ocupan más un espacio pero que sí tienen un lugar" (420). 
al gobierno por su nepotismo, su corrupción, y su impunidad, y cambiaron los patrones tradicionales de la movilización social. En lugar de las clásicas reuniones organizadas por partidos políticos o por sindicatos dominadas por performances públicas de masculinidad, las Marchas del Silencio se parecían notablemente a las acciones colectivas que las Madres de la Plaza de Mayo habían iniciado 13 años antes en la ciudad de Buenos Aires. En Catamarca, los manifestantes comenzaron a realizar caminatas pacíficas alrededor de la plaza central de la ciudad de Catamarca cada jueves demandando justicia y rendición de cuentas. Estas acciones colectivas introdujeron una nueva forma de protesta en esta ciudad periférica. En una sociedad tradicional con sistemas de dominación cuasifeudal, estas acciones colectivas desafiaban la legitimidad de las instituciones públicas. Las marchas de base incluían ciudadanos de clases medias y trabajadoras apoyados por líderes carismáticos católicos que denunciaban la corrupción de la familia Saadi y de la jerarquía política. Las marchas perseguían la instalación de nuevos patrones de control político basado en un sistema abierto, con protección de los derechos civiles y del estado de derecho.

La primera marcha fue organizada por un grupo de compañeras de María Soledad pocos días después de su muerte. Martha Pelloni se convirtió en la mentora de las jóvenes organizadoras y recibió información relevante de testigos que no querían acudir directamente a las autoridades por miedo a las represalias. Las primeras tres marchas contaron con un promedio de 7000 asistentes. En una ciudad de 122000 habitantes donde la mayoría de éstos son económicamente dependientes del gobierno de la provincia, es una cifra sorprendente. Pero a medida en que el encubrimiento se hizo evidente, las marchas llegaron a atraer hasta 30000 manifestantes. Durante el primer año después del homicidio, más de 50 marchas se llevaron a cabo. La protesta pública puso en entredicho la credibilidad 
de todo el sistema judicial que no proveía una versión convincente de los hechos. Las demandas que las marchas abanderaban incluían no sólo la sustitución del sistema nepotista que gobernaba la provincia sino también la puesta en escena de nuevos criterios para la vida pública. Los clásicos lugares de representación se volvieron obsoletos dado que la ciudadanía se había instalado en el centro del escenario.

Las marchas fueron, sobre todo, esfuerzos de mujeres. Las mujeres, algunas de ellas de sólo diecisiete y dieciocho años de edad, las organizaban. Una monja las conducía, y se dramatizaban los tipos de virtudes asociadas a las mujeres: silencio, moderación, pasividad. Se exhibían cuerpos femeninos de adolescentes en uniformes escolares grises con cruces de oro en el pecho. En estas marchas, María Soledad se representaba como una más de estas estudiantes de uniforme gris, con su pelo oscuro recogido en una cola de caballo. Esta figura era opuesta y yuxtapuesta a la imagen de ella como prostituta que tanto Luque como Tula habían tratado de establecer insatisfactoriamente. No es una coincidencia, entonces, que Martha Pelloni siempre se refiriera a ella como la nena y que sus compañeras insistieran en utilizar el sobrenombre "Sole" cuando hablaban con periodistas. De las marchas, la figura de María Soledad surgió como la de una adolescente, que debía haber sido protegida por la ley en vida y que debía ser tratada con respeto después de su muerte.

\section{Estrategias de resistencia}

Los movimientos sociales deben ser concebidos como procesos sociales más que como grupos particulares de personas que buscan metas específicas. Los movimientos sociales se definen ya sea por la identidad de sus miembros (teoría de los nuevos movimientos sociales) o por las capacidades de orga- 
nizar acciones colectivas (teoría de movilización de recursos). En el enfoque del nuevo movimiento social el elemento decisivo de acción colectiva es el interrogante de quién moviliza, mientras que la pregunta crítica que distingue los movimientos sociales en el enfoque de movilización de recursos es cómo la acción colectiva se desarrolla y se transforma en dichos movimientos. ${ }^{19}$ En esencia, el debate actual sobre la formación de protesta social y movimientos populares manifiesta la necesidad de integrar estos dos enfoques. Tanto las estrategias de recursos y de organización y las capacidades para movilizar, como la construcción de una identidad a través del sentido de comunidad generados por estas acciones colectivas, son fundamentales para que los nuevos actores sociales enfrenten con éxito los mecanismos de control social.

En el nuevo movimiento social de Catamarca, ambos elementos pueden ser localizados. Sin el liderazgo de Martha Pelloni, el apoyo de una institución decisiva como la Iglesia católica, y la red de estudiantes, hubiese sido virtualmente imposible concebir las marchas. Pero había una fuente igualmente importante para la protesta. Los ciudadanos de Catamarca desafiaron su papel como "sujetos" del gobierno nepotista. Ellos construyeron la colectividad de verdaderos ciudadanos, una nueva noción de "nosotros". La protección de derechos era su pancarta, pero su principio unificador fue la construcción de su nueva identidad colectiva. En esencia, era el rito de iniciación hacia la ciudadanía.

Dos grupos significativos fueron fundamentales en la movilización: mujeres y estudiantes. Como fue el caso con las Madres de la Plaza de Mayo, la movilización de mujeres en Catamarca se inició del modelo de participación en la esfera pública donde el género era neutral. En su papel de hijas, esposas y madres que adquirieron legitimación en el reclamo de los

${ }^{19}$ Una buena discusión de las dos principales teorías sobre movimientos sociales puede encontrarse en Joe Foweraker. 
derechos de protección para sus hijos. Dado que la Iglesia no podía aislar a los niños de esos peligros (después de todo, María Soledad era una estudiante de una escuela católica), había un interés para entrar en el espacio público desde el papel tradicional de protector familiar, realzando el reclamo de los derechos civiles básicos. En este proceso se creó entre las mujeres una nueva solidaridad. ${ }^{20}$ Las mujeres tenían el derecho de enfrentar patrones de abuso y reclamar nuevos espacios. Sus identidades como hijas, esposas, maestras y madres les permitieron participar en un nuevo movimiento. Su participación, a la vez, reafirmó dichas identidades y les dio una nueva voz. La chinita sexualmente disponible, pobre y de piel oscura, era un símbolo que no pertenecía en la nueva era de derechos equitativos. Estudiantes del Colegio del Carmen y San José, así como de otras escuelas tanto católicas como estatales, también desempeñaron un papel decisivo en la movilización. Las estudiantes proporcionaron la legión inicial de participantes. Más aún, las marchas partían desde la escuela, generando un compromiso mayor entre pares. El papel central de las estudiantes facilitó la acción colectiva y otorgó mayor fuerza al movimiento social. Desde una perspectiva material y estratégica, la movilización estudiantil fue un recurso de liderazgo muy valioso.

Los estudiantes que participaron en el movimiento ejemplificaban los cambios radicales que habían ocurrido en Catamarca. Como una ciudad periférica, estaba altamente influenciada por tendencias culturales que emanaban de Buenos Aires. Sólo un par de años antes del asesinato de María Soledad, únicamente existía un único canal de la televisión local. Pero para mediados de los ochenta los canales de televisión se habían multiplicado, el número de tiendas de video había crecido y la cultura de consumo había permeado los patrones tradicio-

\footnotetext{
${ }^{20}$ Para profundizar en los roles de las mujeres en movimientos sociales, véanse Safa 1990 y también Jelín 1990.
} 
nales. Los jóvenes catamarqueños, expuestos a productos culturales y normas sociales de Buenos Aires, entraron en contacto con avances tecnológicos que les permitieron incluirse en la recientemente democratizada comunidad imaginada del país. ${ }^{21}$

Sin embargo, estas transformaciones se enfrentaban con una realidad social que no permitía materializar expectativas de mayor acceso a productos. La estructura ocupacional de la provincia y su deprimida economía no presentaban un futuro prometedor para las nuevas generaciones. Catamarca no tiene universidad, y la migración a las grandes ciudades parecía ser la mejor alternativa para aquellos que podían pagarlo. No obstante, Catamarca se mantenía como el lugar donde todo parecía funcionar en oposición al proceso nacional. No tenía una economía dinámica, no existían atracciones culturales, y funcionaba de acuerdo con modelos anticuados de moral sexual.

El éxito de los hijos de las familias acomodadas y privilegiadas en Catamarca pasaba por vivir la mitad de su tiempo en Buenos Aires y después repetir los patrones típicos de consumo de las ciudades grandes en sus visitas a Catamarca. El consumo de drogas penetró algunos de esos círculos. Catamarca

${ }^{21}$ García Canclini argumenta que en América Latina el discurso de modernismo tuvo un componente prometedor de equidad y progreso representado por los intentos de educar a la gente, abrir universidades y subsidiar las artes. Por el contrario, el posmodernismo y la era del capitalismo global están caracterizados por la propia idea de educación y el establecimiento de patrones culturales. En esta era de economías de mercado, se supone que los consumidores deciden qué consumir, y los proyectos educativos son vistos con desconfianza. Catamarca a principios de los noventa es un caso ejemplar de esta tendencia: los únicos dos cines de la ciudad habían cerrado y la televisión reinaba. No existe ningún incentivo a crear nuevos esfuerzos culturales, y en una instancia exacerbada de lo que sucede en el resto del país, los chismes sobre la gente rica y famosa dominan la prensa. Especialistas en comunicación como Silvio Waisbord están estudiando la creación de una élite política que se relaciona con miembros del negocio del espectáculo, con sobredosis de relaciones sexuales y gustos caros y exquisitos. Es en el contexto del empobrecimiento económico, cultural y moral, así como la glamorización de negocio del espectáculo que el caso de María Soledad toma nuevas proporciones: María Soledad se convierte en el "cordero de Dios que expía los pecados del mundo", y la zanja donde aventaron su cuerpo, en un santuario para los creyentes. 
se volvió una región importante de narcotráfico y producción, algunos de sus policías y figuras políticas estaban involucradas en el narcotráfico. Para una nueva generación de adolescentes en Catamarca, los efectos de nuevos patrones de consumo y expectativas, junto con la falta de oportunidades, generaron nuevos espacios para la protesta popular. Los jóvenes reaccionaron inmediatamente cuando supieron que el novio de María Soledad no era directamente responsable del asesinato, y que ella había muerto en una fiesta donde habían asistido los hijos de figuras públicas pudientes y acomodadas. La movilización tuvo difusión en los niveles local y nacional y logró acabar con la hegemonía de la familia Saadi en la provincia y el encarcelamiento de culpables de familias poderosas.

Las repercusiones impactaron también el statu quo político y en la Iglesia, y simbólicamente presagiaron procesos nacionales. La impunidad e ineficiencia judicial actual en Argentina, así como el futuro incierto para una vasta generación de jóvenes desempleados, se encuentran incrustados actualmente en la agenda nacional. En el largo plazo, éstos pueden representar estallidos potenciales de disturbios sociales. En el centro del escenario se encuentra la débil administración de los derechos civiles, sociales y económicos. Esto puede explicar el altísimo rating del juicio televisado casi seis años después del asesinato. El caso de María Soledad ejemplifica un punto de inflexión decisivo en la democracia argentina. El homicidio de María Soledad expuso la debilidad de una sociedad en transformación, debilidad que el capitalismo de mercado abierto y las elecciones regulares han sido incapaces de resolver.

\section{La muerte de María Soledad}

En el artículo “Chandra's Death”, Ranajit Guha analiza un texto legal bengalí del siglo XIII que analiza una serie de declaraciones 
jurídicas realizadas en relación con la muerte causada por el aborto de una mujer llamada Chandra. Leyendo el documento a contrapelo, Guha reconstruye un argumento convincente de cómo la moral patriarcal sirvió para forzar a Chandra a someterse a un aborto peligroso y cómo esa misma moral reescribe luego como criminal el esfuerzo de mujeres en su familia para proveer a Chandra de hierbas abortivas, acompañarla durante el aborto, su dolorosa convalecencia y finalmente su muerte. Al proveer este análisis, Guha mismo está recuperando como historia cada detalle de la vida diaria que no llega hasta los libros de historia pero que sí documenta la historia de los subalternos:

Porque cuando una víctima comienza a percibirse como objeto de la injusticia, está poniéndose en el rol de crítica del sistema que la victimiza. Y cualquier acción que comienza en esa crítica contiene los elementos de una práctica de resistencia. ${ }^{22}$

La paradoja intrínseca en la notoriedad de María Soledad - ella quería ser una modelo rica y famosa, y adquirió la fama después de un asesinato brutal- es el germen mismo de la práctica de la resistencia que siguió después de su muerte. Esta práctica articuló una crítica de los modelos de desarrollo desigual que hemos asociado con el capitalismo global y la posmodernidad. La difusión del diario íntimo de María Soledad presentaba a una adolescente preocupada por la belleza y el éxito financiero. Sus ejemplos a seguir eran las modelos de Buenos Aires a quienes ella veía en la televisión, no la monja tenaz que dirigió la lucha para aclarar su asesinato, o su madre criando siete hijos en una situación de carencia. María Soledad se volvió una mártir no porque fuera virgen, o porque fuera una adolescente excepcional, sino porque su homicidio simbolizaba un tipo de violencia e impunidad que las Madres

22 Guha 1988, 165. 
de la Plaza de Mayo habían enseñado a la Argentina a reconocer. Y en su crítica sobre la élite política, los manifestantes también peleaban contra la pobreza, la corrupción política, el narcotráfico y contra esa brecha cada vez mayor entre ricos y pobres.

El cadáver de María Soledad fue arrojado a una zanja al costado de una ruta muy transitada entre Catamarca y el pequeño pueblo en el valle donde María Soledad y su novio Luis Tula vivían. Dejar así el cuerpo tenía como propósito que lo encontraran y de esta manera contar la historia que protegería a aquellos que lo habían ubicado allí. La desfiguración del cuerpo, la excesiva cantidad de cocaína que contenía, y la brutalidad que exhibía parecían sugerir ritos satánicos o bien un ajuste de cuentas entre narcotraficantes. ${ }^{23}$ Como el homicidio es un delito poco común en Catamarca, la policía no está entrenada para trabajar sobre el lugar del delito. Los asesinos estaban suficientemente cerca del sistema legal para pensar que eran impunes. A través de diferentes estrategias de comunicación con los medios buscaron culpar a la víctima apoyándose en un discurso de género donde una mujer desnuda siempre levanta sospechas. O por lo menos eso pensaron.

Los amplísimos públicos del sinfín de programas norteamericanos sobre investigación de homicidios como Law and Order y CSI están familiarizados con el concepto del cadáver como texto. Un cuerpo es encontrado, y dentro de unas horas cuenta una historia que ayuda a los investigadores a descifrar los detalles de la muerte: los dientes, los huesos y la carne humana son las piezas de una historia como rompecabezas que los especialistas interpretan y codifican en un texto narrativo que intenta reconstruir la identidad de la víctima y también la del homicida. Esta narrativa se transforma en un documento legal que puede ser utilizado en la corte.

${ }^{23}$ La segunda autopsia concluyó que la cocaína le fue inyectada al cuerpo de María Soledad después de su muerte. 
Revisemos los distintos pasos. Un cuerpo es encontrado, la prensa lo reporta, los forenses lo leen, y el sistema judicial utiliza la narrativa de hechos como texto para declarar culpabilidad e inocencia. Cada paso de este proceso está marcado por la credibilidad de los profesionales involucrados: reporteros, forenses, abogados, jueces. En Catamarca, la sospecha y la desconfianza marcaron cada paso del proceso. La narrativa que el cadáver de María Soledad producía para el sistema legal no era digna de la confianza para los catamarqueños, quienes finalmente se resistieron a esta narrativa de los hechos y crearon una narrativa de resistencia. ${ }^{24}$

Cuando se empezó a cuestionar al círculo que asistía a las fiestas en la casa de Guillermo Luque, ellos volvieron su dedo acusatorio sobre María Soledad. Esperaban que sus testimonios sobre la promiscuidad de María Soledad probaran que había sido la artífice de su propia muerte y de su propia tragedia por sus fallas morales. La élite provincial sentía que María Soledad era desechable dado que era mujer, porque era pobre y porque era de piel oscura. Los catamarqueños que asistían a las marchas sentían que ella tenía derecho a ser protegida, y que el fracaso del gobierno provincial en la provisión de protección y castigo los volvía incompetentes para gobernar. En ningún otro lugar se hacía tan evidente la diferencia en la apreciación

${ }^{24}$ La opinión pública en Argentina había estado influenciada por el debate de la patología forense y el análisis de cadáveres de las víctimas del terrorismo de Estado de mediados de los años ochenta. Las Abuelas de la Plaza de Mayo abanderaban la necesidad de la patología forense y del potencial científico para determinar las identidades de los niños desaparecidos y de los niños nacidos en cautiverio. También habían utilizado el análisis de los cadáveres de mujeres embarazadas secuestradas para determinar si estas mujeres habían dado a luz a sus bebés en cautiverio. La práctica de desenterrar cadáveres de tumbas no registradas y de cementerios clandestinos era apoyada por las Abuelas de la Plaza de Mayo, pero opuesta por un grupo de las Madres de la Plaza de Mayo, quienes argumentaban que el recuperar cadáveres únicamente serviría para tapar el hecho de las desapariciones al desviar la atención hacia las víctimas de abusos contra los derechos humanos y no a los asesinos. Este hecho dividió a las Madres de la Plaza de Mayo y finalmente produjo una escisión en el movimiento. 
de lo ocurrido como en la forma en que ambos grupos hablaban sobre María Soledad.

Los círculos del gobierno siempre describían a María Soledad en términos sexuales. En el mejor de los casos era presentada como una adolescente sobresexualizada, sin ningún tipo de supervisión paterna. En el peor de los escenarios ella era descrita como una mujerzuela cuyo cadáver despedía mal olor. Luis Tula, en su declaración ante el juez, argumentó que él se negó a que ella se subiera a su automóvil la noche de su desaparición debido a que "olía a pescado". Esta referencia al olor vaginal de una mujer utilizada en círculos machistas suele sugerir que una mujer es promiscua y/o sucia - frecuentemente ambas cosas- ${ }^{25}$ Esta escena del automóvil fue repetida ad nauseam en el juicio y en las cámaras de televisión. La escena, en reiteradas presentaciones, aparece siempre de la misma manera: María Soledad se acerca al automóvil de Tula y habla con él a través de la ventana pero no se sube al automóvil. Él se horroriza por el olor que emana y parte. Sin tener en cuenta la veracidad de la descripción, la narrativa en sí misma tiene el tufo del peor estilo de sexismo. En la historia occidental, el cuerpo femenino se ha visto como un depositario de horror y monstruosidad. La descripción sexual de la misma María Soledad apunta a lo que está ausente de todas las narraciones que la llevan hacia un trágico final: no hay ningún tipo de ternura en ninguna de las descripciones de la adolescente dada por el hombre que tuvo relaciones sexuales consensuales con ella y

25 Nosotros consideramos que esta repugnancia hacia los fluidos corporales producidos por una mujer se relaciona con el miedo al deseo femenino, lo que evidencia la secreción de fluidos. Page du Bois historiza el cuerpo femenino desde la Antigüedad clásica como depositario de una verdad que requiere ser extraída a través de la violencia: "El cuerpo de un esclavo y el cuerpo de una mujer están marcados como propiedad del amo; el sujeto de la historia en la ciudad antigua, el varón griego, gobernaba sobre sus subordinados, animales, esclavos bárbaros, y mujeres, que eran vistos como similares en su calidad subalterna. Al igual que los cuerpos de los esclavos, tatuados con señales de propiedad y origen, los cuerpos femeninos eran metafóricamente escritos por sus amos" (90). 
de los hombres que la violaron. Para oponerse de esta monstruosa imagen, las marchas multiplicaron a María Soledad en cientos de adolescentes en uniformes escolares de color gris, cuya mera presencia en las calles de la ciudad de Catamarca reforzaba la ausencia de María Soledad.

En 1996 más de 300000 personas marcharon en Bélgica en desafío al Estado. Dos hermanas jóvenes habían sido encontradas muertas de hambre en un sótano después de que la policía y otras agencias gubernamentales habían fracasado en localizarlas a pesar de que tenían información concreta que los hubiera llevado hacia el asesino. Como en el caso de María Soledad, pero en circunstancias completamente distintas, un tipo particular de indignación movilizó a la gente: el fracaso del Estado de cumplir con sus obligaciones.

En el capitalismo posindustrial y de mercado abierto, la expectativa de protección y de justicia, en general, no ha desaparecido (Friedman). Habermas y Offe insisten en que la dificultad en reconciliar democracia de masas con capitalismo crea una "crisis de ingobernabilidad". Formas tradicionales de representación política (partidos políticos, sindicatos y otras representaciones corporativas) parecen incapaces de canalizar las nuevas demandas de la ciudadanía. A pesar de que las nuevas formas de capitalismo salvaje globalizado han disminuido las expectativas de los ciudadanos de un Estado económicamente condescendiente, las manifestaciones también sugieren que las expectativas de los ciudadanos en torno a la protección de los derechos civiles en países recientemente democratizados se han incrementado. Dado que los canales tradicionales de representación no responden generalmente a estas nuevas demandas, dos escenarios alternativos son posibles: un "abandono" de parte del Estado —esto es, la atomización de grupos subalternos que dejan la lucha en la búsqueda de beneficios y de participación en la vida nacional; tal es el caso del levantamiento en Chiapas- o el surgimiento de movimientos sociales que buscan 
un Estado que responda y sea capaz de proveer los derechos básicos. Éste es el caso de las Marchas del Silencio. Éstas presagiaron una búsqueda nacional de un sistema judicial responsivo, es decir, que garantice el fin de privilegios especiales, y que dé cauce a las demandas por un Estado que sea capaz tanto de proteger a sus ciudadanos como de hacer cumplir la ley en términos equitativos.

La élite política de Catamarca se enfrentó a nuevas formas de entendimiento del papel de la mujer en el país y especialmente del papel de la mujer joven y pobre. Ésta esperaba poder construir una imagen de María Soledad como víctima de sus propias decisiones. En cambio, Catamarca la visualizó como una víctima de un sistema corrupto y comparó su muerte con la de Jesucristo en la cruz. Desde entonces, otros casos de homicidios donde se involucran mujeres jóvenes en Argentina han producido respuestas colectivas entre los ciudadanos que han aprendido a "leer entre líneas" las versiones oficiales de los hechos y a desafiar a las mismas instituciones que presuntamente los protegen.

Un par de días antes de que los militares derrocaran al gobierno constitucionalmente electo de la presidenta Isabel Martínez de Perón en marzo de 1976, las fuerzas armadas publicaron un anuncio en los principales periódicos del país. En él, un soldado joven de ojos azules veía directamente hacia los ojos del lector. Arriba de la fotografía se leían las palabras: "Estás velando por nosotros". El significado del verbo velar resume la misma contradicción del papel de las instituciones en Argentina: velar por significa proteger, estar despierto y alerta mientras alguien más duerme; por lo tanto, el soldado está protegiendo. Sin embargo, velar también tiene otro significado: velar a significa llorar la muerte de alguien, estar despierto toda la noche anterior al entierro de un muerto. Tomando el segundo significado, velar el anuncio ocultaba la rampante represión que seguía: el soldado estaba inaugurando el duelo, 
sugiriendo la muy extendida destrucción que seguía. El movimiento que creció alrededor del caso de María Soledad ejemplifica la crisis de credibilidad de las instituciones en Argentina, instituciones que buscan proteger pero que acaban oprimiendo.

En la formación del movimiento social de Catamarca, se delinearon nuevas identidades, las antiguas se reforzaron, y se establecieron nuevos patrones de organización social. Las protestas populares en Catamarca trascendieron los trágicos eventos de una víctima y el escándalo político que le siguió. Fue un paso crucial en la construcción simbólica de la ciudadanía, que puso a prueba los límites de la gobernabilidad.

\section{REFERENCIAS}

Bouvard, Marguerite Guzmán, 1994. Revolutionizing Motherhood: The Mothers of the Plaza de Mayo, Wilmington, Delaware, Scholarly Resources.

Chambliss, W. J. y R. B. Seidman, 1982. Law, Order and Power, Reading, Massachusetts, Addison-Wesley.

Cotterrell, Roger, 1984. The Sociology of Law: An Introduction, London, Butterworths.

Diamond, Larry, 1992. "Economic Development and Democracy Reconsidered", The American Behavioral Scientist, 35: 4-5, 450-489.

Du BoIs, Page, 1991. Torture and Truth, New York, Routledge.

Elster, Jon, 1989. The Cement of Society: A Study of Social Order, Cambridge, Cambridge University Press.

Escobar, Arturo y Sonia Álvarez, eds., 1992. The Making of Social Movements in Latin America: Identity, Strategy, and Democracy, Boulder, Colorado, Westview.

FILC, Judith, 1997. Entre el parentesco y la política: familia y dictadura, 1976-1983, Buenos Aires, Biblos.

FoweraKer, Joe, 1995. Theorizing Social Movements, London, Pluto. Franco, Jean, 1985. "Killing Nuns, Priests, Women and Children", en On Signs, ed. Marshall Blonsky, Baltimore, Maryland, Johns Hopkins University Press. 
Friedman, L., 1985. Total Justice. Boston: Russell Sage.

García Canclini, Néstor, 1995. Consumidores y ciudadanos: Conflictos multiculturales de la globalización, México, Grijalbo.

GuнA, Ranajit, 1988. "Chandra's Death", Subaltern Studies, V, Nueva Delhi, Oxford University Press, 135-165.

Habermas, Jürgen, 1996. Between Facts and Norms: Contributions to a Discourse Theory of Law and Democracy, Cambridge, Massachusetts, MIT Press.

JELín, Elizabeth, 1990. Women and Social Change in Latin America, London, Zed Books.

Mainwaring, Scott, 1999. "Transitions to Democracy and Democratic Consolidations: Theoretical and Comparative Issues", en Issues in Democratic Consolidation, eds. Mainwaring, O'Donnell y Valenzuela.

—, Guillermo O’Donnell y Samuel Valenzuela, eds., 1999. Issues in Democratic Consolidation, Notre Dame, Indiana, University of Notre Dame Press.

Marshall, T. H., 1950. Citizenship and Social Class, Cambridge, Cambridge University Press.

Morandini, Norma, 1991. Catamarca, Buenos Aires, Planeta.

O'Donnell, Guillermo, 1993. 'On the State, Democratization, and Some Conceptual Problems: A Latin American View with Some Glances at Post-communist Countries", World Development, 21: 8, 1355-1369.

—, 1999. "Polyarchies and the (Un) Rule of Law in Latin America: A Partial Conclusion", en The (Un) Rule of Law and the Unprivileged in Latin America, ed. Juan E. Méndez, Guillermo O'Donnell, y Paulo Sérgio Pinheiro, Notre Dame, Indiana, University of Notre Dame Press, 303-339.

- y Philippe Schmitter, 1986. "Tentative Conclusions about Uncertain Democracies", Transitions from Authoritarian Rule: Prospects for Democracies, 4, Baltimore, Maryland, Johns Hopkins University Press,

OfFe, Claus, 1987. Contradictions of the Welfare State, Cambridge, Massachusetts, MIT Press.

Olson, Mancur, 1965. The Logic of Collective Action, Cambridge, Massachusetts, Harvard University Press. 
Przeworski, Adam, 1992. Democracy and the Market: Political and Economic Reforms in Eastern Europe and Latin America, Cambridge, Inglaterra, Cambridge University Press.

- . "The Games of Transition", en Issues in Democratic Consolidation, ed. Mainwaring, O’Donnell, y Valenzuela.

Rey, Alejandra y Luis Pazos, 1991. No llores por mí, Catamarca: La intriga política de un crimen, Buenos Aires, Sudamericana.

SAFA, Helen, 1990. "Women's Social Movements in Latin America", Gender and Society 4:3, 354-369.

TILly, Charles, 1984. "Social Movements and National Politics", State Building and Social Movements, Ann Arbor, University of Michigan Press.

Touraine, Alain, 1995. ¿Qué es la democracia?, trad. Horacio Pons, Buenos Aires, Fondo de Cultura Económica.

WasiBrod, Silvio, 1995. El gran desfile: campañas electorales y medios de comunicación en la Argentina, Buenos Aires, Sudamericana.

Zicolillo, Jorge, 1991. Los Saadi, historia de un feudo: del 45 a María Soledad. Buenos Aires, Legasa. 